\title{
Diverted Domino Reactivity in Tertiary Skipped Diynes. A Convenient Access to Polyfunctionalized Cyclohexadienones and Multivalent Aromatic Scaffolds.
}

\author{
David Tejedor, ${ }^{[\mathrm{a}][\mathrm{b}]} *$ Sara López-Tosco,${ }^{[\mathrm{a}][\mathrm{b}]}$ Javier González-Platas, ${ }^{[\mathrm{c}]}$ Fernando García- \\ Tellado
}

Domino reactions ${ }^{[1]}$ constitute single-operation, multi-step processes able to generate two or more bonds under a constant set of reaction conditions. Usually, they transform simple starting materials into more complex chemical entities utilizing networks of construction reactions. ${ }^{[2]}$ This property makes them excellent synthetic tools to carry out molecular construction with atom-,${ }^{[3]}$ redox ${ }^{[4]}$ and step-economy. ${ }^{[5]}$ The sequential order by which these multi-step processes are performed (the reaction manifold) ultimately determines the chemical outcome of the process and therefore, the topology of the final product (the skeletal connectivity). In the last years, we have focused our efforts in the use of small, readily-accessible, densely functionalized platforms for the diversity-oriented domino generation of privileged structural motives with biological relevance. ${ }^{[6]}$ Skipped diynes $\mathbf{1}^{[7]}$ constitute an example of such platforms (Figure 1). They are conveniently synthesized in one step and multigram scale from alkyl propiolates and acid chlorides via a triethylamine assisted multicomponent $\mathrm{A}_{2} \mathrm{BB}{ }^{\prime} 4 \mathrm{CR}^{[8]}$ This modular origin ensures a convenient grade of functional diversity on the tertiary $\mathrm{sp}^{3}$-center (diversity domain). The reactivity profile of the platform is defined by the two alkynoate units and the propargyl ester function (reactivity domain). Recent reports from our group ${ }^{[9]}$ have shown how these $\mathrm{C}_{7}$-units can be selectively transformed into polysubstituted pyrroles $\mathbf{4},{ }^{[9 a]}$ 1,4-diazepane derivatives $\mathbf{5}^{[9 b]}$ or pyrazoles $\mathbf{6},{ }^{[\mathrm{b}]}$ when they are made to react with primary amines, 1,2-diamines and hydrazines respectively (Scheme 1).

[a] Dr. D. Tejedor, Dr. S. López-Tosco, Dr. F. Garcia-Tellado

Instituto de Productos Naturales y Agrobiología

Departamento de Química Biológica y Biotecnología

Consejo Superior de Investigaciones Científicas

Astrofísico Francisco Sánchez 3

38206- La Laguna-Tenerife-Spain

Fax: int-34922260135

E-mail: fgarcia@ipna.csic.es; dtejedor@ipna.csic.es

Homepage: www.ipna.csic.es/departamentos/qbb/qb

[b] Dr. D. Tejedor, Dr. S. López-Tosco, Dr. F. García-Tellado

Instituto Canario de Investigación del Cáncer

Homepage: www.icic.es

[c] Dr. J. González-Platas (Crystallographer)

Servicio de Difracción de Rayos X

Departamento de Física Fundamental II

Universidad de La Laguna

Avda. Astrofísico Francisco Sánchez 2,

38204 La Laguna, Tenerife, Spain.

Supporting information for this article is available on the WWW under http://www.angewandte.org

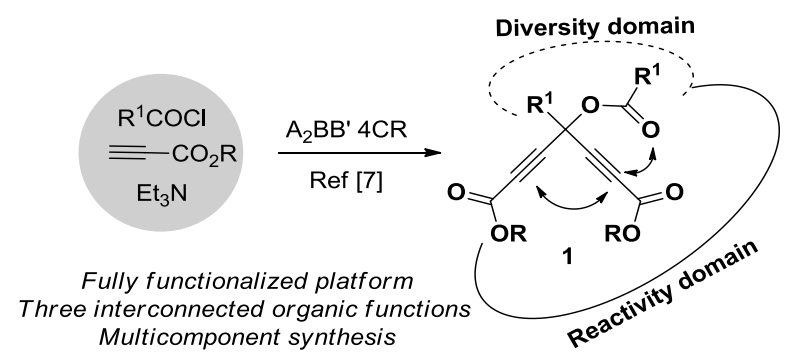

Figure 1. Synthesis and properties of skipped diynes 1.

These heterocycles are generated by $\mathrm{N}$-cyclization of the corresponding enamine intermediates $2(\mathrm{Nu}=\mathrm{PgNH}$, $\mathrm{HNCH}\left(\mathrm{R}^{2}\right) \mathrm{CH}\left(\mathrm{R}^{3}\right) \mathrm{NH}_{2}$ and $\mathrm{PgNH}-\mathrm{NH}$ respectively). Although the reactivity profile of enamine $\mathbf{2}$ can be characterized by the two canonical representations $\mathbf{2}$ (neutral) and $\mathbf{3}$ (zwitterionic), the $\mathrm{N}$ cyclization controls the main domino reactivity pattern of this molecule (Nu-driven domino processes). We envisioned that an alternative $\mathrm{O}$-enolate-driven domino reactivity pattern biased by the mesomeric form 3 could take place if this $\mathrm{N}$-cyclization could be blocked. Under these conditions, the O-cyclization reaction of the enamine 2 would provide the cyclic oxonium ion 7, which

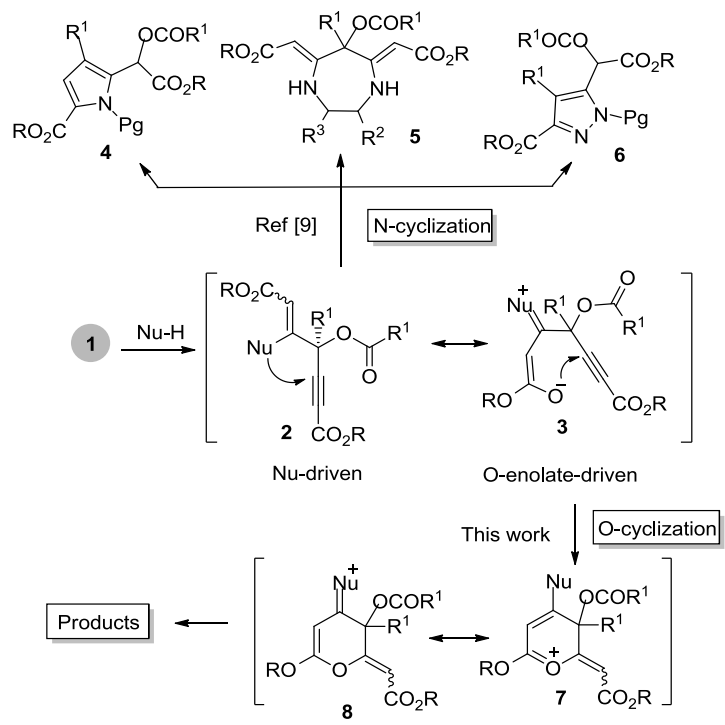

Scheme 1. Diverted domino reactivity of tertiary skipped diynes $\mathbf{1}$. 
could be conveniently transformed into different products. This new scenario would enable the development of new domino processes and therefore, it would increase the synthetic power of these $\mathrm{C}_{7}$-platforms. The chemical accomplishment of this goal requires: 1) disfavoring the $\mathrm{N}$-cyclization; 2) favoring the shift of the electronic density from the nitrogen to the oxygen atom; 3 ) stabilizing the cyclic oxonium ion $\mathbf{7}$ by a redistribution of the electronic deficiency via the canonical form $\mathbf{8}$ and 4) a polar and protic medium to favor the separation of charges produced going from 2 (neutral) to $\mathbf{3}$ (zwitterionic) and to assist in the acid-base quenching of the O-cyclization reaction. Whereas secondary amines could meet the first three requirements through the interconversion between their corresponding iminium and enamine forms, ${ }^{[10]}$ alcohols would guarantee the fourth condition. In this communication we report the feasibility of this conceptual approach and we show how it can be implemented for the diversity-oriented synthesis of polysubstituted cyclohexadienones and multivalent aromatic scaffolds bearing a survey of valuable functionalities decorating the ring.

The hypothesis was assessed using the reaction of diyne 1a with different secondary amines under different reaction conditions [Eq. (1)]. Table 1 summarizes the main experimental results, ${ }^{[11]}$ using two representative secondary amines: pyrrolidine (9a), as a representative example of cyclic and highly nucleophilic secondary amines, and dibenzylamine $(\mathbf{9 b})$ as a representative example of acyclic, sterically demanding secondary amines with reduced nucleophilicity. We began this work studying the reaction of diyne 1a (1 eq) and pyrrolidine (9a) (1 eq) in dichloromethane. After several assays, it was found that the reaction at room temperature for 16 hours afforded the mixture of cyclohexadienones derivatives 10aa and 11aa although in low yield (Table 1, entry 1). When the amount of pyrrolidine was doubled (to adjust the stoichiometry to the formation of 11aa), the reaction exclusively generated the compound 11aa in 67\% yield (entry 2). The structures of these two products, ${ }^{[12]}$ which were unexpected, constituted experimental evidence of a reactivity shift in the diynic platform, and they established the chemical outcome for the novel domino reaction pathway elicited from these platforms. According to our initial hypothesis, alcohols would be beneficial solvents for this domino reaction. It was gratifying to find that the use of $\mathrm{MeOH}$ or $\mathrm{EtOH}$ as solvent allowed obtaining the diamine derivative 11aa in nearly quantitative yield (entries 34). On the other hand, the reaction of diyne $1 \mathrm{a}$ with dibenzylamine (9b) showed to be solvent dependent. Whereas the reaction in $\mathrm{EtOH}$ generated the mixture of monoamines 10ab $(5 \%)$ and 12ab $(5 \%)$ together with the diamine 11ab (86\%) (entry 5), the reaction in $\mathrm{MeOH}$ afforded the monoamine 10ab (39\%) and diamime 11ab (53\%) (entry 6).

With these results at hand, it soon became evident that strong nucleophilic amines and/or less nucleophilic alcoholic solvents favored the formation of diamine derivatives 11, while low nucleophilic amines and a stronger nucleophilic alcoholic solvent favored the formation of monoamine derivatives $\mathbf{1 0}$.

When dibenzylamine was used, the presence of product 12ab bearing an ethoxy group, revealed the participation of the solvent (EtOH), which was further confirmed by crossover experiments. Moreover, it was also confirmed that $\mathbf{1 0}$ and $\mathbf{1 2}$ did not interconvert under these reaction conditions (See SI for details). Interestingly, the dilution of the methanolic reaction increased the formation of the monoamine 10ab up to $79 \%$ yield (entry 7). Further experiments with the dibenzylamine derivatives $\mathbf{9 b - d ,}$

Table 1. Domino reaction of diyne 1a and secondary amines 9a-d. ${ }^{[a]}$

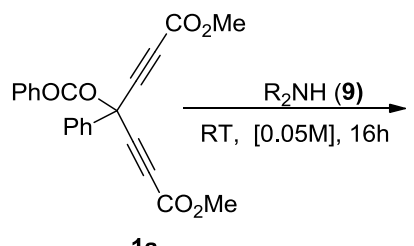

1a

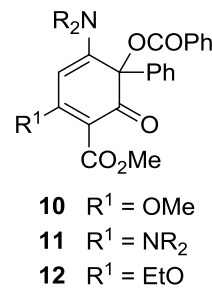

(1)

\begin{tabular}{cccccc}
\hline Entry & Solvent & Amine & & $\mathbf{1 0}(\%)$ & $\mathbf{1 1}(\%)$ \\
\hline 1 & $\mathrm{CH}_{2} \mathrm{Cl}_{2}$ & $\mathrm{C}_{4} \mathrm{H}_{8} \mathrm{NH}^{[\mathrm{b}]}$ & $\mathbf{9 a}$ & 30 & 9 \\
2 & $\mathrm{CH}_{2} \mathrm{Cl}_{2}$ & $\mathrm{C}_{4} \mathrm{H}_{8} \mathrm{NH}$ & “ & n.d. ${ }^{[\mathrm{c}]}$ & 67 \\
3 & $\mathrm{MeOH}$ & $\mathrm{C}_{4} \mathrm{H}_{8} \mathrm{NH}$ & “ & n.d. & $>99$ \\
4 & $\mathrm{EtOH}$ & $\mathrm{C}_{4} \mathrm{H}_{8} \mathrm{NH}$ & “ & n.d. & $>99$ \\
5 & $\mathrm{EtOH}$ & $\mathrm{Bn}_{2} \mathrm{NH}$ & $\mathbf{9 b}$ & $10^{[\mathrm{e}]}$ & 86 \\
6 & $\mathrm{MeOH}$ & $\mathrm{Bn}_{2} \mathrm{NH}$ & $\mathbf{9 b}$ & 39 & 53 \\
7 & $\mathrm{MeOH}^{[\mathrm{d}]}$ & $\mathrm{Bn}_{2} \mathrm{NH}$ & $\mathbf{9 b}$ & 79 & 21 \\
8 & $\mathrm{MeOH}^{[\mathrm{d}]}$ & $\mathrm{PMDBA}^{[\mathrm{f}]}$ & $\mathbf{9 c}$ & 67 & 33 \\
9 & $\mathrm{MeOH}^{[\mathrm{d}]}$ & $\mathrm{PNDBA}^{[\mathrm{g}]}$ & $\mathbf{9 d}$ & $93^{[\mathrm{h}]}$ & 7 \\
\hline
\end{tabular}

[a] Reaction conditions: diyne $(0.10 \mathrm{mmol})$, amine $(0.22 \mathrm{mmol})$, solvent $(2 \mathrm{~mL})$. [b] $0.11 \mathrm{mmol}$. [c] n.d. = non detected. [d] $0.01 \mathrm{M}$. [e] Roughly equimolecular mixture of monoamides 11ab and 12ab. [f] PMDBA = bis(4-methoxyphenyl)methanamine. [g] PNDBA = bis(4-nitrophenyl)methanamine. [h] 50\% conversion $(50 \%$ r.s.m)

which share a similar steric environment at the nitrogen center but feature different electronic properties, ${ }^{[13]}$ showed a clear relationship between the nucleophilicity of the amine and the ratio of monoamine 10/diamine 11 in the reaction mixtures (entries 79). The reaction with amine 9d, the worst nucleophile, was very slow and it afforded monoamine10ad in $47 \%$ yield $(50 \%$ of conversion) after 7 days at room temperature. We did not observe other chemical entities different to products and starting materials in the reaction crude. This fact seems to point to an early rate limiting step in this domino reaction.

The chemical efficiency and the complexity generation power of this reaction exceeded all our expectations. The reaction generated up to four new bonds ( $2 \mathrm{C}-\mathrm{N}, 1 \mathrm{C}-\mathrm{C}, 1 \mathrm{C}=\mathrm{O})$ and one ring with excellent atom economy and an operationally simple protocol.

The set of experimental data can be rationalized through the O-enolate driven domino manifold outlined in Scheme 2. The scenario comprises two reaction pathways (a and b) diverging from a common intermediate IV. The pathway a is launched by the addition of a second amine unit on the cyclic oxonium ion IV to give the orthoaminal $\mathbf{V}$, which rearranges to aminal VII via the formation of the immonium-enolate VI. The elimination of $\mathrm{R}^{2} \mathrm{OH}$ from VII delivers the diamino derivative 11. The much less favored elimination of $\mathrm{R}_{2} \mathrm{NH}$ would generate the monoamine derivative 10. The pathway $\mathbf{b}$ is triggered by the addition of the solvent on IV to give the corresponding orthoester derivative (not shown), which rearranges to the mixed ketal VIII, which in turn eliminates alcohol to give the statistical mixture of monoamines $\mathbf{1 0}$ and 12. Thus, whereas pathway a affords diamine $\mathbf{1 1}$ as the main compound, route $\mathbf{b}$ only delivers monoamine $\mathbf{1 0}$ (or $\mathbf{1 2}$ if methanol is not used as the alcoholic solvent). The pathway $\mathbf{a}$ is triggered by a bimolecular reaction (rate $=k_{a}[\mathbf{I V}][$ amine $]$ ) and consequently, it would be benefited by high nucleophilic amines, high concentration, low nucleophilic solvents and low temperatures. On the other hand, route $\mathbf{b}$ is launched by a pseudo 
first order reaction (rate $=k_{a p}[\mathbf{I V}], k_{a p}=k_{b}$ [solvent]) and it would be benefited by low nucleophilic amines, dilution, nucleophilic solvents and higher temperature. While pyrrolidine (9a) meets the requirements of route $\mathbf{a}$ and it exclusively affords diamine derivative 11aa ${ }^{[14]}$ with independence of the reaction conditions, dibenzylamine (9b) can react following either of the two pathways, and the chemical outcome of the reaction will come determined by the stoichiometry, solvent, concentration and temperature. Because tertiary dibenzylamines could be considered masked forms of primary amines (hydrogenolysis renders the free primary amine), the installation of these motives into the cyclohexadienones $\mathbf{1 0}$ and $\mathbf{1 1}$ would increase their synthetic value. With this idea in mind, we next undertook the selective transformation of diyne 1a into cyclohexadienones 10ab and 11 ab.

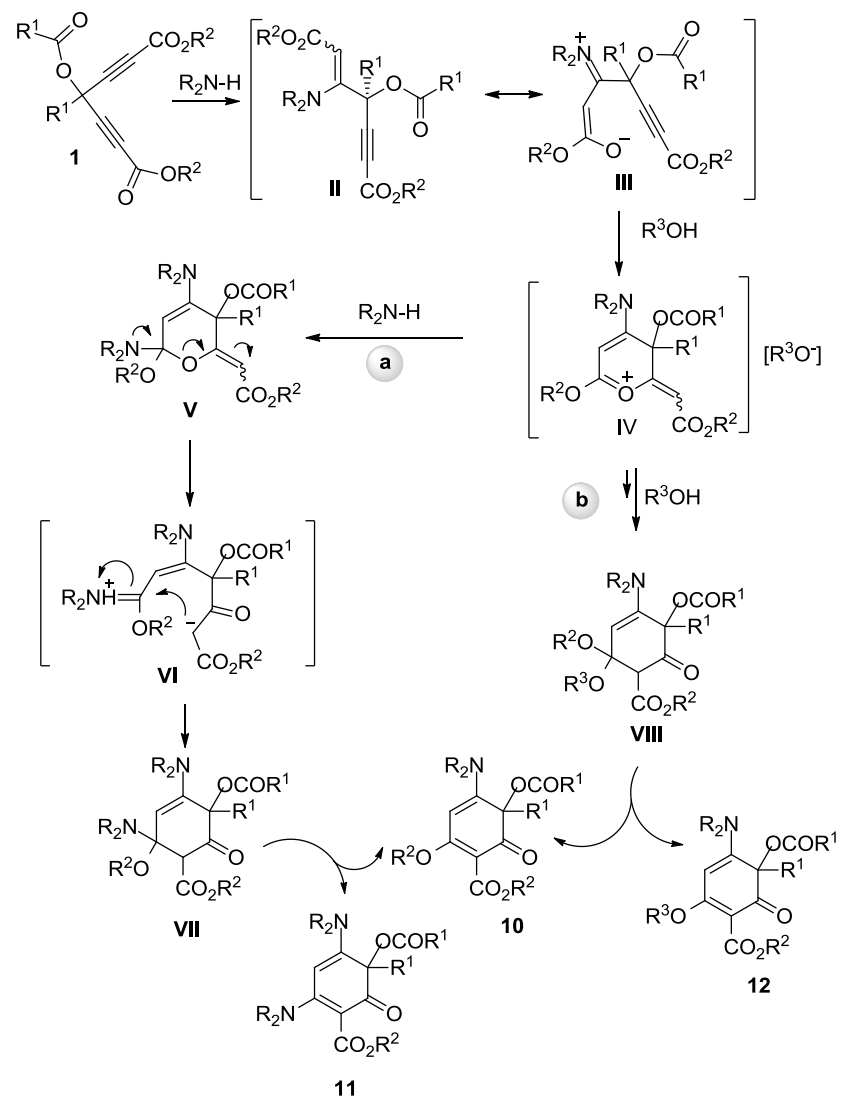

Scheme 2. O-enolate driven domino mechanistic proposal.

After some experimental work, we found that the reaction of diyne 1a with one equivalent of dibenzylamine (9b) could be selectively funneled toward route $\mathbf{b}\left[\mathrm{MeOH}(0.01 \mathrm{M}), 65^{\circ} \mathrm{C}, 16 \mathrm{~h}\right]$ to afford monoamine 10ab in $95 \%$ yield (Eq. (2), method A) (Table 2, entry 1). The scope of this domino reaction was explored using the set of skipped diynes shown in Table 2. The reaction was tolerant with different functionalities decorating the diynes $\mathbf{1 b}$-i, rendering the corresponding monoamine derivatives 10bb-ib in excellent yields. Although the tertiary $\mathrm{sp}^{3}$-center on the skipped diyne does not participate directly in the reaction, it exerts steric hindrance on the alkynoate moiety. This steric effect resulted in a lowering of the reactivity of aliphatic diynes $\mathbf{1} \mathbf{j}$ and 1k which needed more forcing conditions (3 days) to be efficiently converted into their corresponding monoamine derivatives $10 \mathbf{j b}$ and $\mathbf{1 0 k b}$ (entries 21 and 22).

Table 2. Domino reaction of diyne $\mathbf{1}$ and dibenzyl amine (9b)

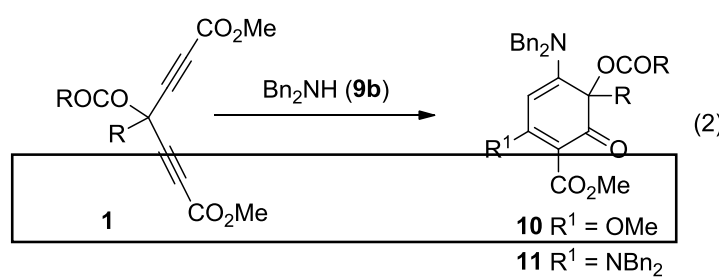

Method A: $\mathrm{MeOH}[0.01 \mathrm{M}], 65^{\circ} \mathrm{C}, 16 \mathrm{~h}$

Method B: $\mathrm{CH}_{2} \mathrm{Cl}_{2} / \mathrm{EtOH} / \mathrm{H}_{2} \mathrm{O} /(4 / 4 / 1),[0.05 \mathrm{M}], \mathrm{RT}, 16 \mathrm{~h}$

\begin{tabular}{|c|c|c|c|c|c|}
\hline Entry & $\mathrm{R}$ & & Method & $10(\%)^{[\mathrm{a}]}$ & $11(\%)^{[\mathrm{a}]}$ \\
\hline 1 & $\mathrm{Ph}$ & $1 \mathrm{a}$ & $A^{[b]}$ & 95 & \\
\hline 2 & & & $\mathbf{B}^{[\mathrm{c}]}$ & & 94 \\
\hline 3 & & & $\mathbf{B}^{[\mathbf{d}]}$ & & 91 \\
\hline 4 & $2-\mathrm{Cl}-\mathrm{C}_{6} \mathrm{H}_{4}$ & $1 b$ & $\mathbf{A}$ & 84 & \\
\hline 5 & & & B & & 74 \\
\hline 6 & 3-Cl- $\mathrm{C}_{6} \mathrm{H}_{4}$ & $1 \mathrm{c}$ & $\mathbf{A}$ & 93 & \\
\hline 7 & & & B & & 86 \\
\hline 8 & 4-Cl- $\mathrm{C}_{6} \mathrm{H}_{4}$ & 1d & $\mathbf{A}$ & 92 & \\
\hline 9 & & & B & & 86 \\
\hline 10 & 4-F- $\mathrm{C}_{6} \mathrm{H}_{4}$ & 1e & $\mathbf{A}$ & 95 & \\
\hline 11 & & & $\mathbf{A}^{[\mathrm{e}]}$ & 94 & \\
\hline 12 & & & B & & 88 \\
\hline 13 & 4-BiPh & 1f & $\mathbf{A}$ & 93 & \\
\hline 14 & & & B & & 80 \\
\hline 15 & 4-Me- $\mathrm{C}_{6} \mathrm{H}_{4}$ & $1 \mathrm{~g}$ & $\mathbf{A}$ & 96 & \\
\hline 16 & & & B & & 87 \\
\hline 17 & $3-\mathrm{MeO}-\mathrm{C}_{6} \mathrm{H}_{4}$ & $1 \mathrm{~h}$ & $\mathbf{A}$ & 93 & \\
\hline 18 & & & B & & 85 \\
\hline 19 & 3,5-diMeO- $\mathrm{C}_{6} \mathrm{H}_{3}$ & $1 \mathrm{i}$ & $\mathbf{A}$ & 94 & \\
\hline 20 & & & B & & 81 \\
\hline 21 & $i \operatorname{Pr}$ & $1 \mathrm{j}$ & $\mathbf{A}$ & $85^{[\mathrm{f}]}$ & \\
\hline 22 & $\mathrm{C}_{6} \mathrm{H}_{11}$ & $1 \mathrm{k}$ & $\mathbf{A}$ & $84^{[\mathrm{f}]}$ & \\
\hline 23 & & & B & & $40^{[\mathrm{g}]}$ \\
\hline
\end{tabular}

With the monoamine derivatives 10ab-kb at hand, we explored the selective formation of the corresponding diamine derivatives 11ab-kb. Preliminary experiments had showed that the reaction of dibenzylamine (9b) and diyne $\mathbf{1 a}$ in $\mathrm{EtOH}$ generated the diamine 11ab in good yield $(86 \%)$ but contaminated with significant amounts of monoamine derivatives 10-12ab (10\%)(Table 1,entry 5). According to Scheme 2, it was apparent that if the nucleophilicity of the EtOH could be lowered then route $\mathbf{b}$ could be diminished and the yield of diamine $\mathbf{1 1}$ would be increased. ${ }^{[15]} \mathrm{H}_{2} \mathrm{O}$ was envisioned as a convenient co-solvent as it was expected that it would lower the nucleophilicity of $\mathrm{EtOH}$ through coordination while it would increase the polarity of the reaction medium. After several experimental trials, we found that the mixture of EtOH- $\mathrm{H}_{2} \mathrm{O}$ (4/1) was optimal for the selectivity of the reaction, but unfortunately, the low solubility of the lipophilic diynes $\mathbf{1 b}-\mathbf{k}$ in this aqueous media compromised the reaction efficiency. Fortunately, it was found that the addition of $\mathrm{CH}_{2} \mathrm{Cl}_{2}$ to the aqueous solvent cocktail brought the diynes 1a-k into solution increasing the reaction efficiency without eroding the 
selectivity of the reaction. (Eq. (2), method B). Under these conditions, aromatic diynes 1a-i uniformly reacted with two equivalent of dibenzylamine to give the corresponding diamine derivatives 11ab-ib in good to excellent yields (Table 2). Aliphatic substituted diynes were not convenient substrates for this reaction. The steric hindrance exerted by the tertiary $\mathrm{sp}^{3}$ center on the alkynoate moiety comprised a kinetic barrier difficult to overcome. Under these conditions, diyne $1 \mathbf{k}$ needed a week at room temperature to deliver the diamine 11 ak in only $40 \%$ yield (entry 23 ).

It is important to highlight that these reactions can be performed at multigram scales without significant erosion in the reaction efficiency (Table 2, entries 3 and 11).

Cyclohexadienones $\mathbf{1 0}$ and $\mathbf{1 1}$ represent densely functionalized building (synthetic) blocks with a polyvalent reactivity profile. Among the wide set of imaginable transformations that could be addressed on these platforms, we show herein their direct transformation into multivalent aromatic platforms 13 and 14 [Eq. (3)], which constitute valuable examples of salicylate derivatives ${ }^{[16]}$ bearing a privileged biaryl ${ }^{[17]}$ motive $(\mathrm{R}=\mathrm{Ar})$ and one (13) or two (14) amine groups in their structures. This transformation takes advantage of the presence of the tertiary aryloate group in $\alpha$-position to the non-enolizable carbonyl group. Reduction of this ketone to the corresponding alcohol would provide the corresponding phenol derivative by the concomitant elimination of the aroylate group. The reduction of this hindered ketone was problematic but it was conveniently achieved using an excess of $\mathrm{Mg}$ in refluxing $\mathrm{EtOH}$ to afford the corresponding phenol derivative in moderated to good yields [Eq. (3)]. ${ }^{[18]}$ The amine deprotection under standard conditions $\left(\mathrm{H}_{2}-\right.$ $\mathrm{Pd}(\mathrm{OH})_{2}$ ) rendered the corresponding amine-free aromatic scaffolds $\mathbf{1 3}$ and 14 in excellent yields. Gratifyingly, this two-step process could be efficiently performed without isolation of the phenol intermediate with a good overall efficiency for both platforms (Table 3). In addition, the whole transformation could be performed at multigram scale (entry 2 ).

Table 3. Synthesis of multivalent aromatic platforms $\mathbf{1 3}$ and $\mathbf{1 4}{ }^{\text {[a] }}$

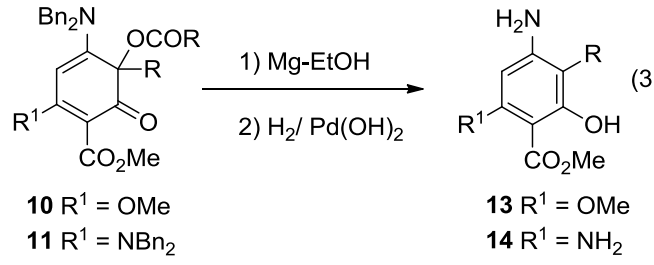

\begin{tabular}{ccccc}
\hline Entry & St. material & $\mathrm{R}$ & Product & $(\%)^{[\mathrm{b}]}$ \\
\hline 1 & $\mathbf{1 0 a b}$ & $\mathrm{Ph}$ & $\mathbf{1 3 a}$ & 75 \\
2 & $\mathbf{1 0 e b}$ & $4-\mathrm{F}-\mathrm{C}_{6} \mathrm{H}_{4}$ & $\mathbf{1 3 e}$ & $68^{[\mathrm{c}]}$ \\
3 & $\mathbf{1 0 h b}$ & $3-\mathrm{MeO}-\mathrm{C}_{6} \mathrm{H}_{4}$ & $\mathbf{1 3 h}$ & 62 \\
4 & $\mathbf{1 0 i b}$ & $3,5-\mathrm{diMeO}_{4} \mathrm{C}_{6} \mathrm{H}_{3}$ & $\mathbf{1 3 i}$ & 75 \\
5 & $\mathbf{1 0 k b}$ & $\mathrm{C}_{6} \mathrm{H}_{11}$ & $\mathbf{1 3 k}$ & 48 \\
6 & $\mathbf{1 1 a b}$ & $\mathrm{Ph}$ & $\mathbf{1 4 a}$ & 76 \\
7 & $\mathbf{1 1 e b}$ & $4-\mathrm{F}-\mathrm{C}_{6} \mathrm{H}_{4}$ & $\mathbf{1 4 e}$ & 74 \\
8 & $\mathbf{1 1 f b}$ & $4-\mathrm{BiPh}_{2}$ & $\mathbf{1 4 f}$ & 50 \\
9 & $\mathbf{1 1 g b}$ & $4-\mathrm{Me}-\mathrm{C}_{6} \mathrm{H}_{4}$ & $\mathbf{1 4 g}$ & 75 \\
10 & $\mathbf{1 1 h b}$ & $3-\mathrm{MeO}-\mathrm{C}_{6} \mathrm{H}_{4}$ & $\mathbf{1 4 h}$ & 63 \\
11 & $\mathbf{1 1 i b}$ & $3,5-\mathrm{diMeO}_{4} \mathrm{C}_{6} \mathrm{H}_{3}$ & $\mathbf{1 4 i}$ & 77 \\
\hline
\end{tabular}

[a]See experimental section. [b] Isolated yields. [c] $7.0 \mathrm{mmol}$ scale
It is important to note that the substitution pattern decorating structures $\mathbf{1 3}$ and $\mathbf{1 4}$ is not directly accessible by the established methodologies in the construction of biaryl ${ }^{[19]}$ and salicylatebased structures ${ }^{[20]}$ using simple and ready available precursors. In addition, the metal-free installation of two aromatic unprotected amine groups, which are relevant functional motifs in pharmacological and new materials research, is an appealing value of this methodology when compared with described metal catalyzed aminations. ${ }^{[21]}$

In summary, we have shown that tertiary skipped diynes $\mathbf{1}$ can be efficiently and selectively transformed into polysubstituted cyclohexadienones $\mathbf{1 0}$ and $\mathbf{1 1}$ via a divergent O-enolate driven novel domino process. The manifold uses benzylamine as the secondary amine to generate up to four new bonds $(2 \mathrm{C}-\mathrm{N}, 1 \mathrm{C}-\mathrm{C}$, $1 C=O$ ) and one ring with excellent atom economy and an operationally simple protocol. Moreover, we have shown how these polysubstituted cyclohexadienones are suitable platforms for the access to multivalent aromatic scaffolds decorated with a rich functional pattern comprising: a biaryl (Ar, Ar), a salicylate (1,2$\mathrm{OH}, \mathrm{COOH})$, an arylphenol (1,2-OH, Ar), a biarylamine (1,2-NH, $\mathrm{Ar})$ and an anthranilate $(1,2-\mathrm{NH}, \mathrm{COOH})$. This substitution pattern is well suited for the generation of natural-product-like libraries throughout functional pairing strategies. ${ }^{[22]}$ Such study is ongoing in our lab.

\section{Experimental Section}

General procedure for the synthesis of monoamines 10. Table 2, Method A. Dibenzylamine $(0.55 \mathrm{mmol})$ was added to a solution of diyne 1a $(188 \mathrm{mg}, 0.50$ $\mathrm{mmol})$ in $\mathrm{MeOH}(50 \mathrm{~mL})$ and the reaction mixture was stirred overnight at reflux. After removing the solvent under reduced pressure the products were purified by flash column chromatography (silica gel, EtOAc/ $\mathrm{CH}_{2} \mathrm{Cl}_{2}$ ) to yield 10ab. In certain cases it is useful to recrystallize the final product to remove small amounts of unreacted dibenzylamine $\left(\mathrm{CH}_{2} \mathrm{Cl}_{2}\right.$ and $1.5 \%$ EtOAc/Hexane). Alternatively, the chromatography can be avoided if the amount of subproduct cyclohexadienones $\mathbf{1 1}$ is not significant. Recrystallization typically affords the final product with yields similar to the reported ones in table 2.

General procedure for the synthesis of monoamines 11. Table 2, Method B. Dibenzylamine $(1.05 \mathrm{mmol})$ was added to a solution of diyne $1 \mathrm{1a}(188 \mathrm{mg}, 0.50$ $\mathrm{mmol})$ in a mixture of $\mathrm{EtOH} / \mathrm{CH}_{2} \mathrm{Cl}_{2} / \mathrm{H}_{2} \mathrm{O}(4 \mathrm{~mL} / 4 \mathrm{~mL} / 1 \mathrm{~mL})$ at room temperature. The reaction mixture was stirred overnight. After removing the solvent under reduced pressure the products were purified by flash column chromatography (silica gel, EtOAc/ $\mathrm{CH}_{2} \mathrm{Cl}_{2}$ ) to yield $\mathbf{1 1 a b}$

General procedure for the synthesis of salicylates 13 and 14. Cyclohexadienone 11ab $(738 \mathrm{mg}, 1.00 \mathrm{mmol})$ was dissolved in $\mathrm{MeOH}(100 \mathrm{~mL})$. Mg turnings (70 $\mathrm{mmol}$ ) were added and the mixture was heated overnight at $65^{\circ} \mathrm{C}$. After the reaction mixture was cooled to $0^{\circ} \mathrm{C}, 6 \mathrm{M} \mathrm{HCl}$ was added slowly. Once the methanol was evaporated under reduced pressure, the aqueous phase was extracted twice with $\mathrm{CH}_{2} \mathrm{Cl}_{2}$. After removing the solvent at reduced pressure the crude products were dissolved in $\mathrm{MeOH} / \mathrm{CH}_{2} \mathrm{Cl}_{2}$ 1:1 $(100 \mathrm{~mL}) .20 \% \mathrm{Pd}(\mathrm{OH})_{2} / \mathrm{C}(90 \mathrm{mg})$ was added and the reaction mixture was hydrogenated with $\mathrm{H}_{2}(1 \mathrm{~atm})$ at room temperature for 16 hours. After filtration with celite and removal of the solvent under reduced pressure, the products were purified by flash column chromatography (silica gel, EtOAc/hexane) to afford 14a.

\section{Acknowledgements}

This research was supported by the Spanish MICINN and the European RDF (CTQ2008-06806-C02-02), the Spanish MSC ISCIII (RETICS RD06/0020/1046), FUNCIS (PI 43/09). S. L.-T. thanks Spanish MEC for a FPU grant. Authors thank technician Ms. Anna Jurado Varona for her experimental assistance.

Keywords: anthranilate $\cdot$ cyclohexadienone $\cdot$ domino $\cdot$ salicylate $\cdot$ skipped diynes.

[1] F. Tietze, G. Brasche, K. M. Gericke in Domino reactions in Organic Synthesis, Wiley-VCH: Weinheim, 2006. 
[2] Construction reactions are defined as those reactions that form skeletal bonds. See: a) J. B. Hendrickson, J. Am. Chem. Soc. 1975, 97, 5784-5800; b) T. Gaich, P. S. Baran, J. Org. Chem. 2010, 75, 4657-4673.

[3] B. M. Trost, Science 1991, 254, 1471-1477.

[4] N. Z. Burns, P. S. Baran, R. W. Hoffmann, Angew. Chem. 2009, 121, 28962910; Angew. Chem. Int. Ed. 2009, 48, 2854-2867.

[5] P. A. Wender, V. A. Verma, T. J. Paxton and T. H. Pillow, Acc. Chem. Res. 2008, 41, 40-49.

[6] For selected contributions, see: a) D. Tejedor, G. Méndez-Abt, L. Cotos, M. A. Ramirez, F. García-Tellado, Chem. Eur. J. 2011, 17, 3318-3321; b) L. León, C. Ríos-Luci, D. Tejedor, E. Pérez-Roth, J. C. Montero, A. Pandiella, F. Garcia-Tellado, J. M. Padrón, J. Med. Chem. 2010, 53, 3835-3839; c) D. Tejedor, G. Méndez-Abt, F. García-Tellado, Chem. Eur. J. 2010, 16, 428431; d) D. Tejedor, A. Santos-Expósito, F. García-Tellado, Chem. Eur. J. 2007, 13, 1201-1209; e) D. Tejedor, D. González-Cruz, A. Santos-Expósito, J. J. Marrero-Tellado, P. de Armas, F. García-Tellado, Chem. Eur. J. 2005, 11, 3502-3510; f) D. Tejedor, D. González-Cruz, F. García-Tellado, J. J. Marrero-Tellado, M. L. Rodríguez, J. Am. Chem. Soc. 2004, 126, 8390-8391; g) D. Tejedor, F. García-Tellado, J. J. Marrero-Tellado, P. de Armas, Chem. Eur. J. 2003, 9, 3122-3131

[7] D. Tejedor, S. López-Tosco, J. González-Platas, F. García-Tellado, J. Org. Chem. 2007, 72, 5454-5456.

[8] $\mathrm{A}_{2} \mathrm{BB}$ ' 4CRs refers to a four-component reaction that utilizes two different components ( $\mathrm{A}$ and $\mathrm{B}$ ) to give a product which incorporates into its structure two identical units of component $\mathrm{A}$ and two chemo-differentiated units of component B (B and B'). For full details and more examples of this type of multicomponent reactions: D. Tejedor, F. García-Tellado, Chem. Soc. Rev. 2007, 36, 484-491.

[9] a) D. Tejedor, S. López-Tosco, J. González-Platas, F. García-Tellado, Chem. Eur. J. 2009, 15, 838-842; b) D. Tejedor, S. López-Tosco, J. González-Platas, F. García-Tellado, Chem. Eur. J. 2010, 16, 3276-3280.

[10] For selected reviews, see: a) C. Grondal, M. Jeanty, D. Enders, Nature Chem. 2010, 2, 167-178; b) D. Enders, C. Grondal, M. R. M. Hütl, Angew. Chem. 2007, 119, 1590-1601; Angew. Chem. Int. Ed. 2007, 46, 1570-1581.

[11] From the large number of experimental results obtained from the reaction of diyne 1a with different secondary amines under different reaction conditions, we have collected in Table 1 the most relevant and illustrating results related to this work.

[12] The structures of these compounds were unambiguously assigned by singlecrystal X-ray diffraction analysis. CCDC 820434 and CCDC 820435 contain the supplementary crystallographic data for the structures 10aa and 11aa respectively. These data can be obtained free of charge from The Cambridge Crystallographic Data Centre via www.ccdc.cam.ac.uk/data_request/cif.
[13] $\mathrm{pKa}\left(\mathrm{Bn}_{2} \mathrm{NH}\right)=8.76 ; \mathrm{pKa}(\mathrm{PMDBA}, 9 \mathrm{c})=9.55 ; \mathrm{pKa}(\mathrm{PNDBA}, 9 \mathbf{d})=6.98$ (Calculated using the $\mathrm{ACD} / \mathrm{pKa} \mathrm{dB}$ program).

[14] The reaction of pyrrolidine and related secondary amines with skipped diynes 1 in $\mathrm{EtOH}$ (or $\mathrm{MeOH}$ ) presented a general scope with regard to the diyne. In all the assayed cases, the reactions afforded the corresponding diamine derivatives $\mathbf{1 1}$ in good to excellent yields. These results are not included in this work.

[15] Although $i \mathrm{PrOH}$, a less nucleophilic solvent, was selective in the formation of 11ab (no 10ab was detected) it was less efficient, as only $47 \%$ of the desired product was isolated after 16 hours.

[16] Salicylates constitute core structures of pharmacologically important natural products. S. Bräse, A. Encinas, J. Keck, C. F. Nising, Chem. Rev. 2009, 109 3903-3990.

[17] D. A. Horton, G. T. Bourne, M. L. Smythe, Chem. Rev. 2003, 103, 893-930.

[18] Cl-substituents at the aromatic ring were not tolerated. $\mathrm{Mg} / \mathrm{EtOH}$ reduced the $\mathrm{C}_{\mathrm{sp}^{2}-} \mathrm{Cl}$ to the corresponding $\mathrm{C}_{\mathrm{sp}^{2}-\mathrm{H}}$

[19] For selected reviews: a) J. A. Ashenhurst, Chem. Soc. Rev. 2010, 39, 540548; b) R. Martin, S. L. Buchwald, Acc. Chem. Res. 2008, 41, 1461-1473; c) G. C. Fu, Acc. Chem. Res. 2008, 41, 1555-1564; d) K. C. Nicolaou, P. G. Bulger, D. Sarlah, Angew. Chem. 2005, 117, 4516-4563; Angew. Chem., Int Ed. 2005, 44, 4442-4489; e) J. Hassan, M. Sevignon, C. Gozzi, E. Schulz, M. Lemaire, Chem. Rev. 2002, 102, 1359-1469.

[20] a) M. Dai, Sarlah, M. Yu, S. J. Danishefsky, G. O. Jones, K. N. Houk, J. Am. Chem. Soc. 2007, 129, 645-657; b) H. Feist, P. Langer, Synthesis 2007, 327 347.

[21] J. F. Hartwig, Acc. Chem. Res. 2008, 41, 1534-1544.

[22] For selected reviews see: a) T. E Nilsen, S. L. Schreiber, Angew. Chem 2008, 120, 52- 61; Angew. Chem. Int. Ed. 2008, 47, 48-56; b) W. R. J. D. Galloway, A. Isidro-Llobet, D. R. Spring, Nature Commun. 2010, 1 , doi:10.1038/ncomms1081; c) For a significant breakthrough in this area, see: D. Morton, S. Leach, C. Cordier, S. Warriner, A. Nelson, Angew. Chem. 2009, 121, 110-115; Angew. Chem. Int. Ed. 2009, 48, 104-109.

Received: ((will be filled in by the editorial staff))

Revised: ((will be filled in by the editorial staff)) Published online: ((will be filled in by the editorial staff)) 
Entry for the Table of Contents (Please choose one layout only)

\section{Domino synthesis}

David Tejedor*, Sara López-Tosco, Javier González-Platas, Fernando García-Tellado*.........Page - Page

Diverted Domino Reactivity in Tertiary Skipped Diynes. A

Convenient Access to

Polyfunctionalized

Cyclohexadienones and

Multivalent Aromatic Scaffolds.

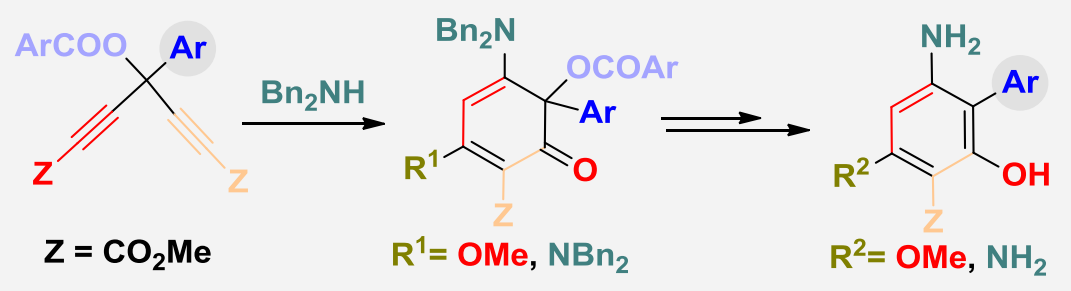

Diverting is the game! A advantage of a novel Onovel domino manifold has enolate driven reactivity been implemented for the pattern discovered for these synthesis of cyclohexadienone diynes. The scaffolds are based scaffolds from tertiary conveniently transformed into skipped diynes and secondary the corresponding multivalent amines. The manifold takes salicylate derivatives. 